\title{
Correction to: Planar Saltwater Analysis for Transparent Electromagnetic Shielding Applications
}

\author{
Duy Tung Phan ${ }^{1} \cdot$ Byungje Lee ${ }^{2} \cdot$ Chang Won Jung ${ }^{1} \mathbb{C}$
}

Published online: 27 April 2021

(c) The Korean Institute of Electrical Engineers 2021

\section{Correction to: \\ Journal of Electrical Engineering \& Technology https://doi.org/10.1007/s42835-021-00747-z}

Due to an unfortunate oversight the acknowledgement section has been omitted. It should read:

Acknowledgements This work was supported by a National Research Foundation of Korea Grant funded by the Korean government (No.2016R1D1A1B02012957).

Publisher's Note Springer Nature remains neutral with regard to jurisdictional claims in published maps and institutional affiliations.

The original article can be found online at https://doi.org/10.1007/ s42835-021-00747-z.

Chang Won Jung

changwoj@snut.ac.kr

Duy Tung Phan

duytungphan@gmail.com

Byungje Lee

bj_lee@kw.ac.kr

1 Graduate School of Nano-IT·Design Fusion, Seoul National University of Science and Technology, 232 Gongneung-ro,

Nowon-gu, Seoul 01811, Korea

2 Department of Electronics and Information Engineering, Kwangwoon University, 20 Kwangwoon ro, Nowon-Gu, Seoul 01897, Korea 